DOI: $10.5800 / G T-2020-11-3-0493$

\title{
GENERAL REGULARITIES OF SEISMIC ACTIVITY OF NORTHERN ARMENIA IN CONNECTION WITH BLOCK STRUCTURE AND TECTONIC ACTIVITY
}

\author{
K.S. Ghazaryan ${ }^{1 \otimes}$, R.S. Sargsyan $\mathbb{1}^{1,2}$
}

\author{
${ }^{1}$ Nazarov Institute of Geophysics and Engineering Seismology, Armenian National Academy of Sciences, 5 V. Sargsyan St, \\ Gyumri 3115, Armenia \\ ${ }^{2}$ Nalbandyan Shirak State University, 4 Paruyr Sevak St, Gyumri 3126, Armenia
}

\begin{abstract}
The study is focused on searching for spatial regularities in the occurrence of earthquake hypocenters in different geological settings in Northern Armenia. Tectonic-geomorphological indices are applied to define the tectonic activity of blocks composing the study area, which was manifested within a long period of time, starting from the neotectonic development period. The blocks are classified accordingly. The regional seismic activity is analysed considering the block structure of the study area. Earthquake focal mechanisms are determined, and dominant displacement trends are identified. Based on the comparative analysis of the blocks' tectonic activity indicators and the locations of seismic events differing in strength, regular patterns of spatial distribution of seismic events are identified. It is established that the earthquake hypocenters of different strength occur in certain block structures; and the predominant types of movements in the earthquake hypocenters are largely determined by types of fault structures. It is emphasized that investigating the blocks' neotectonic activity is important for discovering the general patterns of spatial distribution of seismic events.
\end{abstract}

KEYWORDS: block structure; tectonic activity; earthquake hypocentre; seismic activity; focal mechanism

FOR CITATION: Ghazaryan K.S., Sargsyan R.S., 2020. General regularities of seismic activity of Northern Armenia in connection with block structure and tectonic activity. Geodynamics \& Tectonophysics 11 (3), 595-605. doi:10.5800/GT-2020-11-3-0493 


\title{
ОБЩИЕ ЗАКОНОМЕРНОСТИ СЕЙСМИЧЕСКОЙ АКТИВНОСТИ СЕВЕРНОЙ АРМЕНИИ В СВЯЗИ С БЛОКОВЫМ СТРОЕНИЕМ И ТЕКТОНИЧЕСКОЙ АКТИВНОСТЬЮ ТЕРРИТОРИИ
}

\author{
К.С. Казарян ${ }^{1}$, Р.С. Саргсян ${ }^{1,2}$
}

\author{
${ }^{1}$ Институт геофизики и инженерной сейсмологии им. А. Назарова НАН РА, 3115, Гюмри, ул. В. Саргсяна, 5, \\ Армения \\ ${ }^{2}$ Ширакский государственный университет им. М. Налбандяна, 3126, Гюмри, ул. Паруйра Севака, 4, Армения
}

\begin{abstract}
АННОТАЦИЯ. Статья посвящена изучению пространственных закономерностей приуроченности очагов землетрясений разных категорий к определенным геологическим ситуациям на территории Северной Армении.

С помощью применения разных тектоногеоморфологических показателей определена степень тектонической активности блоковых единиц изучаемой территории за длительный интервал времени (начиная с неотектонического этапа развития), на основе чего проведена классификация блоков.

В статье проведен анализ сейсмической активности территории в контексте ее блокового строения. Построены механизмы очагов землетрясений, с помощью которых установлены преобладающие типы подвижек.

В результате сопоставительного анализа показателей по тектонической активности блоков и различных сейсмических событий выявлены пространственные закономерности приуроченности очагов землетрясений разной величины к определенным блоковым структурам. Установлено, что преобладающие типы подвижек в очагах землетрясений во многом обусловлены типами разломных структур. Подчеркнута важность изучения неотектонической активности блоков в исследовании общих закономерностей пространственного распределения сейсмических событий.
\end{abstract}

КЛЮЧЕВЫЕ СЛОВА: блоковое строение; тектоническая активность; очаг землетрясения; сейсмическая активность; механизм очага

\section{1. ВВЕДЕНИЕ}

Изучение общих закономерностей сейсмической активности является одной из наиболее актуальных задач современной сейсмологии. Важное научное значение таких исследований заключается в выявлении пространственной приуроченности сильных и слабых сейсмических событий к определенным геологическим ситуациям.

Территория Армении, которая выделяется ярко выраженной сейсмической активностью, представляет собой молодую горную страну (нагорье), современный морфоструктурный облик которой был сформирован в недавнем геологическом прошлом, в ходе неотектонического (олигоцен - антропоген) этапа. Сильно дифференцированные неотектонические разрывно-блоковые подвижки, суммарный вертикальный компонент которых, согласно некоторым исследованиям [Simonyan, 1995], местами доходил до 3.0-3.2 км, во многом обусловили сложное мозаично-блоковое строение местности. Особенно ярко это выражается на территории Северной Армении, которая, согласно геоморфологическому районированию, охватывает весь северный складчатый регион.

Исследуемая территория также знаменуется современной активной геодинамикой, что выражается современными тектоническими подвижками и часто фиксируемыми сейсмическими событиями.

Цель данной статьи и ее главная задача заключаются в выявлении пространственных закономерностей сейсмической активности в контексте ее блокового строения и тектонической активности.
С уверенностью можно констатировать, что данная задача также является научной проблемой для изучаемого региона, поскольку этой тематике посвящено несколько научных трудов.

Первенство среди них принадлежит работе А.А. Габриеляна и С.А. Пирузяна [Gabrielyan, Piruzyan, 1972], в которой впервые поднимается вопрос о пространственной приуроченности сильных и слабых землетрясений к определенным структурно-тектоническим зонам. Авторы делают заключение о том, что «более сейсмоактивны районы, характеризуемые дифференцированными и контрастными типами новейших движений. Чем больше изменение знака и скорости новейших и современных движений по простиранию и во времени, т.е. чем больше их градиент, тем выше сейсмоактивность». Далее, в той же работе авторы распространяют это заключение на основные пять геотектонических зон территории Армении.

Авторы настоящей работы придерживаются вышеприведенной точки зрения и считают, что общая картина сейсмической активности территории, которая наблюдается в настоящем, во многом обусловлена именно той структурно-тектонической обстановкой, которая была установлена еще в ходе неотектонического этапа развития территории. Данное обстоятельство особенно важно при изучении сейсмической активности территории в контексте ее блокового строения. Эта проблема может быть объективно решена только при изучении тектонических характеристик каждого из блоков за длительный промежуток времени, когда были сформированы основные структурные черты 
территории. Только при таком подходе возможно выявление некоторых «стабильных» со структурно-тектононической позиции обстановок, при которых возникают благоприятные условия для периодического накопления большого количества тектонических напряжений и возникновения сильных землетрясений или, наоборот, таких обстановок, при которых в основном наблюдаются землетрясения более низкого ранга. Результатом такого исследования может стать наиболее обоснованное и объективное выделение зон возникновения очагов землетрясений и оценка сейсмотектонического потенциала для разных сегментов разломов.

Новизна настоящей работы обусловлена также привлечением уточненных сейсмологических данных. В основе всех ранее проведенных исследований лежали сейсмологические данные из разных каталогов и бюллетеней, которые не выделялись однородностью, поскольку были решены разными системами наблюдений и методами обработки. Более подробно эта проблема изложена в работе [Burmin et al., 2016]. В указанной работе при анализе исходных сейсмологических данных территории Армении было установлено, что, согласно каталогам, эпицентры землетрясений достаточно равномерно распределены по территории. По данным каталогов, в совокупности эпицентров землетрясений не проявляется определенной зональности, т.е. нет закономерности в их приуроченности к определенным геологическим структурам. По такому распределению эпицентров можно предположить отсутствие на территории Армении блоковых структур, что противоречит общепринятому мнению [Volchanskaya et al., 1971; Gabrielyan et al., 1981; Karapetyan, 1988].

C.C. Арефьев в одной из глав своей монографии [Arefiev, 2003], посвященной Спитакскому землетрясению 1988 г., уместно отмечает, что при составлении карты эпицентров землетрясений территории Северной Армении по данным из вышеупомянутых каталогов и бюллетеней за 1964-1988 гг. карта принимает искусственный «решетчатый» вид. Относительно этого автор делает вывод о том, что в каталог были ошибочно внесены также те сейсмические события (энергетический класс порядка 8), которые в действительности являются промышленными взрывами. Данное обстоятельство, как отмечает автор, не дает возможности рассмотреть детально пространственно-временные вариации сейсмичности.

Исходя из вышеизложенных проблем, касающихся локализации очагов землетрясений на исследуемой территории, в настоящей работе применены сейсмологические данные за период 1971-2018 гг., взятые из работы [Burmin et al., 2018], в которой была проведена оценка точности исходных сейсмологических данных каталогов и бюллетеней, в результате чего были отфильтрованы данные с высокой точностью (погрешность определения координат очага не превышает 5 км).

\section{2. МЕТОДЫ ИССЛЕДОВАНИЯ}

В предыдущем разделе мы представили идею, на которой строится данное исследование. Исходя из этого, с целью изучения тектонической активности блоков был применен целый комплекс тектоногеоморфологических показателей. Именно тектоногеоморфологические показатели позволяют составить представление об общих чертах тектонической активности блоков за длительный промежуток времени.

Авторы настоящей работы осознают важность и информативность данных, полученных путем повторного нивелирования и с помощью GPS-станций, роль которых незаменима при изучении современных тектонических подвижек. Однако эти исследования, как правило, не имеют длительного временного охвата, что позволило бы выявить общие закономерности в структурно-тектонической обстановке региона и, тем самым характеризуют лишь мгновение (по геологическим меркам). Кроме того, хорошо известно, что современные вертикальные тектонические подвижки за короткий интервал времени нередко меняют свой знак и тем самым делают невозможным выявление каких-либо долгосрочных тенденций. Последнее довольно четко отмечается в работе С.П. Бальяна, Д.А. Лилиенберга и Е.Е. Милановского [Bal'yan et al., 1989], в которой авторы изучают современные тектонические подвижки сейсмоактивных орогенов территории Армении, отмечая резкое изменение знака (от воздымания к опусканию и обратно) современных вертикальных тектонических движений за довольно короткий интервал времени (25-30 лет).

Для оценки тектонической активности блоков исследуемой территории были применены следующие тектоногеоморфологические показатели: индекс соотношения ширины и глубины долины (Valley floor width - valley height Ratio, $V_{F}$ ), индекс относительной расширенности склонов (Relative Slope Extension Index, $R D E t$ ), показатель густоты линеаментной сети (Lineament Density, $L_{D}$ ), гипсометрический интеграл (Нypsometry Integral, $H I)$, индекс относительной кривизны подножья склона (Mountain Front Sinuosity, $S_{m f}$ ), а также индекс тектонической активности (Index of Active Tectonics, $I A T$ ), который суммирует все вышеперечисленные показатели. Подсчет всех показателей был произведен для каждой блоковой единицы по соответствующей методике [Mahmood, Gloaguen, 2012; Etchebehere et al., 2006; Moussi et al., 2018; Singh et al., 2008; Gentana et al., 2018]. Несколько слов о каждом из примененных геоморфологических индексов.

Подсчет индекса соотношения ширины и глубины долины $\left(V_{F}\right)$ выполняется по следующей формуле:

$$
V_{F}=\frac{2 V_{F W}}{\left(E_{l d}-E_{s c}\right)+\left(E_{r d}-E_{s c}\right)},
$$

где $V_{F W}$ - это ширина дна долины, $E_{l d} E_{r d}$ и $E_{s c}$ - соответственно абсолютные отметки высоты левостороннего, правостороннего крыльев и дна долины. Другими 
словами, эта формула характеризует поперечный профиль долины, который в зависимости от значения индекса меняется от V-образной (при $\mathrm{V}_{\mathrm{F}}<1$ ) к U-образному (при $\mathrm{V}_{\mathrm{F}}>1$ ).

Индекс относительной расширенности склонов (RDEt) подсчитывается следующей формулой:

$$
R D E t=(\Delta H / \Delta L) \cdot \operatorname{In} L,
$$

где $\Delta H$ - это падение реки, $\Delta L$ - длина реки по прямой линии, а $L$ - длина реки по тальвегу. Высокие значения RDEt характеризуют участки с высокой тектонической активностью, что проявляется в высокой крутизне продольного профиля реки и ее длине.

Густота линеаментной сети $\left(L_{D}\right)$ отражает общую расчлененность территории линейными элементами рельефа, которые преимущественно имеют тектоническое происхождение. Отметим, что для подсчета данного показателя нами была применена программа PCI Geomatica, с помощью которой на базе светотеневой модели рельефа были выделены все линейные элементы местности, а дальнейший подсчет был произведен в программе ArcMAP.

Гипсометрический интеграл (HI) является одним из важнейших индексов при оценке тектонической активности территории. Формула подсчета данного индекса представлена ниже:

$$
H I=\left(\text { Elev }_{\text {mean }}-\text { Elev }_{\text {min }}\right) /\left(\text { Elev }_{\text {max }}-\text { Elev }_{\text {min }}\right),
$$

где $E l e v_{\text {mean' }}$ Elev $_{\text {max }}$ и $E l e v_{\text {min }}$ - соответственно среднее, максимальное и минимальное абсолютное значение высоты территории. Из формулы следует, что, чем выше значение $H I$, тем тектонически активнее территория, что выражается в большой разнице между максимальным, средним и минимальным значением абсолютных высот.

Индекс относительной кривизны подножия склона $\left(S_{m f}\right)$ подсчитывается по следующей формуле:

$$
S_{m f}=L_{m f} / \mathrm{L}_{s},
$$

где $L_{m f}$ - длина подножия склона, $L_{s}$ - длина подножия склона по прямой линии. Значение $S_{m f}$ не может быть меньше 1 , следовательно, чем оно ближе к отметке 1 , тем интенсивнее были темпы вертикальных тектонических подвижек.

Следует отметить, что по всем вышеприведенным индексам тектонические единицы исследуемой территории были подвержены классификации, в результате чего они были подразделены на четыре категории: очень активные (1), активные (2), средние (3) и пассивные (4). Более детально это приведено в табл. 1.

Последним является индекс тектонической активности (IAT), который суммирует все остальные индексы. Индекс подсчитывается по следующей формуле:

$$
I A T=S / N,
$$

где $S$ - это сумма категорий всех ранее примененных индексов, а $N$ - количество примененных индексов. Согласно работе [Mahmood, Gloaguen, 2012], по значению
IAT блоки делятся на следующие категории: $1.0<I A T<1.5$ блоки с очень высокой тектонической активностью, $1.5<I A T<2.0$ - блоки с высокой тектонической активностью, $2.0<I A T<2.5$ - блоки со средней тектонической активностью, IAT>2.5 - блоки с низкой тектонической активностью.

Относительно применения сейсмологических данных можно отметить следующее. Расчет механизмов очагов землетрясений по знакам первых вступлений $P$-волн был осуществлен программным комплексом FA [Lander, 2004]. Программа, в частности, позволяет рассчитать азимут из очага на станцию, определить тип сейсмической волны, приходящей в первом вступлении (по заданной модели среды и эпицентральному расстоянию), рассчитать угол выхода луча из очага (для данного типа волны), разделить данные по степени надежности и определить нодальные плоскости, разделяющие направления тектонического сжатия и растяжения.

Расчеты фокальных механизмов производились на стереографической проекции сетки Вульфа для нижней полусферы. Параметры построенных механизмов приведены в следующем разделе в табл. 2.

Таблица 1. Показатели тектонической активности блоков

\begin{tabular}{|c|c|c|c|c|c|c|}
\hline \multirow{2}{*}{$\begin{array}{l}\text { Наиме- } \\
\text { нование } \\
\text { блока }\end{array}$} & \multicolumn{6}{|c|}{$\begin{array}{c}\text { Класс тектонической активности блока } \\
\text { по отдельным тектоногеоморфологическим } \\
\text { показателям }\end{array}$} \\
\hline & $\mathrm{V}_{\mathrm{F}}$ & RDEt & $\mathrm{L}_{\mathrm{D}}$ & $\mathrm{HI}$ & $\mathrm{S}_{\mathrm{mf}}$ & IAT \\
\hline ESMB & 1 & 2 & 2 & 2 & 2 & 1.8 \\
\hline SMBSS & 1 & 1 & 2 & 2 & 1 & 1.4 \\
\hline SMBNS & 1 & 1 & 1 & 1 & 1 & 1 \\
\hline ARB & 2 & 1 & 1 & 1 & 1 & 1.2 \\
\hline MB & 2 & 1 & 1 & 1 & 2 & 1.4 \\
\hline GBSS & 2 & 2 & 2 & 3 & 2 & 2.2 \\
\hline GBNS & 2 & 1 & 1 & 2 & 2 & 1.6 \\
\hline HB & 1 & 1 & 1 & 1 & 1 & 1 \\
\hline PBCS & 1 & 1 & 1 & 1 & 1 & 1 \\
\hline PBES & 1 & 2 & 2 & 2 & 2 & 1.8 \\
\hline PBWS & 3 & 3 & 2 & 2 & 2 & 2.4 \\
\hline TSB1 & 1 & 2 & 2 & 1 & 2 & 1.6 \\
\hline TSB2 & 3 & 2 & 2 & 2 & 3 & 2.4 \\
\hline TSB3 & 3 & 1 & 1 & 2 & 1 & 1.6 \\
\hline LB & 2 & 1 & 1 & 1 & 1 & 1.2 \\
\hline BBES & 2 & 2 & 3 & 2 & 2 & 2.2 \\
\hline BBWS & 1 & 1 & 1 & 1 & 1 & 1 \\
\hline $\mathrm{TB}$ & 3 & 3 & 3 & 3 & 3 & 3 \\
\hline JB & 2 & 1 & 2 & 1 & 1 & 1.4 \\
\hline ABES & 3 & 3 & 2 & 2 & 1 & 2.2 \\
\hline ABWS & 3 & 3 & 3 & 2 & 2 & 2.6 \\
\hline ASHB & 2 & 2 & 3 & 2 & 2 & 2.2 \\
\hline SHB & 3 & 3 & 3 & 3 & 3 & 3 \\
\hline
\end{tabular}
Северной Армении

Table 1. Indicators of tectonic activity of the blocks in Northern Armenia 


\section{3. РЕЗУЛЬТАТЫ ИССЛЕДОВАНИЯ}

В результате была составлена карта тектонической активности блоков Северной Армении (рис. 1), которая отражает структурную и тектоническую обстановку исследуемой территории. В табл. 1, как уже было отмечено, более детально приведены показатели по отдельным блокам.

На исследуемой территории с очень высокой тектонической активностью выделяются: южный и северный сегменты блока Севанского хребта, центральный сегмент Памбакского и западный сегмент Базумского блока, а также Арегунийский, Халабский, Миапорский, Лалварский и Джавахетский вулканические блоки. Высокой тектонической активностью характеризуются: блок Восточно-Севанского хребта, северный сегмент Гугаркского блока, первый и третий сегменты Цахкуняцкого блока, восточный сегмент Памбакского блока. Средней тектонической активностью выделяются: Ашоцкий блок, южный сегмент Гугаркского блока, второй сегмент Цахкуняцкого блока, восточные сегменты
Базумского и Амасийского блоков, западный сегмент Памбакского блока. Низкая тектоническая активность характерна для западного сегмента Амасийского блока, а также Таширского и Ширакского блоков.

По рис. 1 можно заключить, что тектоническая активность блоковых единиц исследуемой территории неоднородна. Местами, особенно в западной части, блоки с очень высокой тектонической активностью граничат с блоками средней и даже низкой активности. В других частях территории между собой граничат в основном блоки очень высокой и высокой активности. Тектонические ситуации такого рода безусловно являются важнейшими предпосылками возникновения сейсмических событий разного характера и величины. Данный факт, по нашему мнению, должен быть принят во внимание и, более того, должен служить той опорной точкой, от которой следует отталкиваться при исследовании пространственных закономерностей сейсмических событий разной величины, при выделении зон возникновения сильных землетрясений и оценке

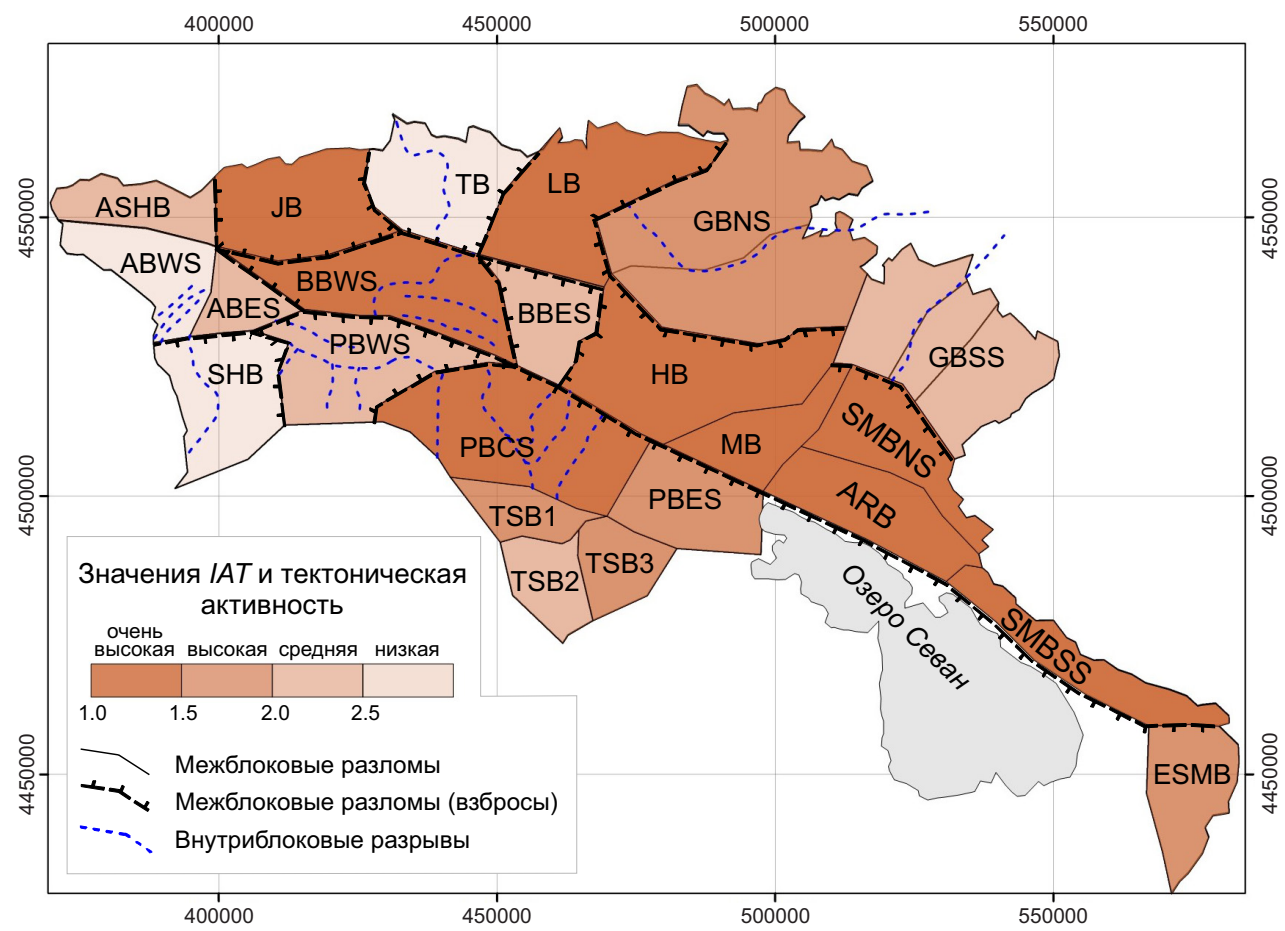

Рис. 1. Карта тектонической активности блоков Северной Армении по значениям IAT.

Блоки: ESMB - блок Восточно-Севанского хребта, SMBSS - южный сегмент блока Севанского хребта, ARB - Арегунийский блок, SMBNS - северный сегмент блока Севанского хребта, GBSS - южный сегмент Гугаркского блока, GBNS - северный сегмент Гугаркского блока, MB - Миапорский блок, НB - Халабский блок, PBES - восточный сегмент Памбакского блока, PBCS центральный сегмент Памбакского блока, PBWS - западный сегмент Памбакского блока, TSB1, TSB2, TSB3 - первый, второй и третий сегменты Цахкуняцкого блока, LB - Лалварский блок, BBES - восточный сегмент Базумского блока, BBWS - западный сегмент Базумского блока, TB - Таширский блок, JB - Джавахетский блок, ASHB - Ашоцкий блок, ABWS - западный сегмент Амасийского блока, ABES - восточный сегмент Амасийского блока, SHB - Ширакский блок.

Fig. 1. Tectonic activity map of Northern Armenia according to IAT values.

Blocks: ESMB - East Sevan ridge block, SMBSS - southern segment of the Sevan ridge block, ARB - Aregunsky block, SMBNS - northern segment of the Sevan ridge block, GBSS - southern segment of the Gugark block, GBNS - northern segment of the Gugark block, MB Miapor block, HB - Khalab block, PBES - eastern segment of the Pambak block, PBCS - central segment of the Pambak block, PBWS western segment of the Pambak block, TSB1, TSB2, TSB3 - first, second and third segments of the Tsakhkunyat block, LB - Lalvar block, BBES - eastern segment of the Bazumi block, BBWS - western segment of the Bazumi block, TB - Tashir block, JB - Javakheti block, ASHB - Ashot block, ABWS - western segment of the Amasi block, ABES - eastern segment of the Amasi block, SHB - Shirak block. 
(a)

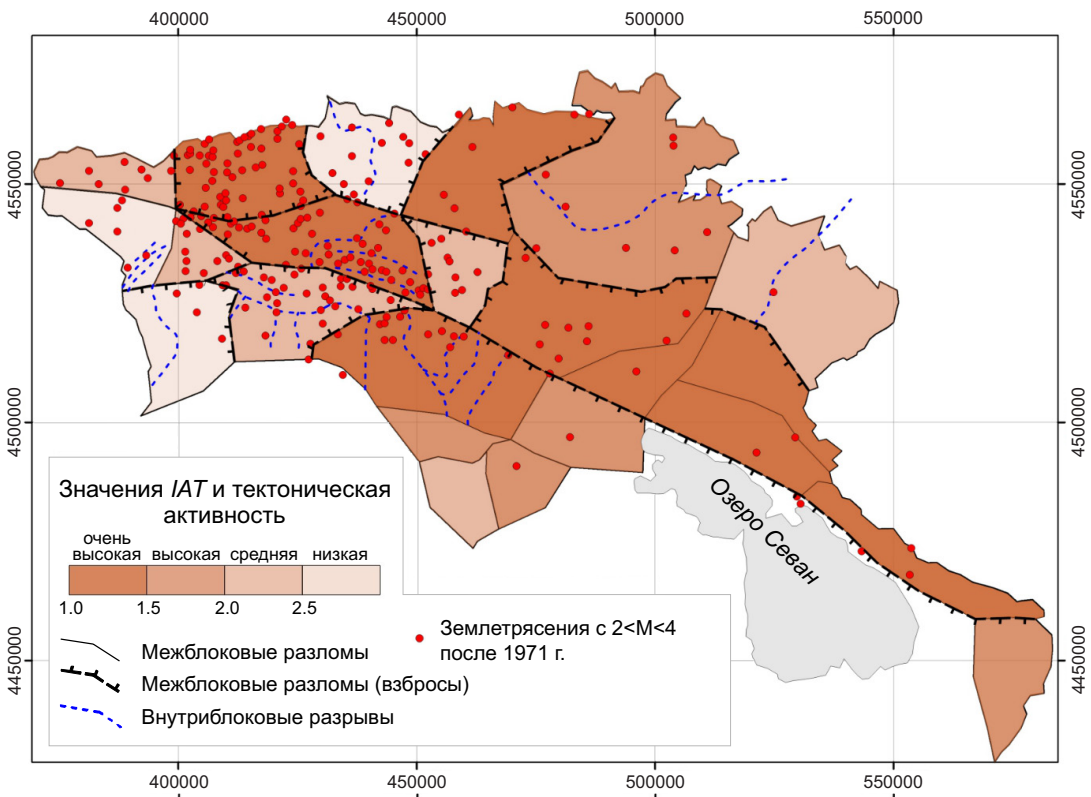

(б)

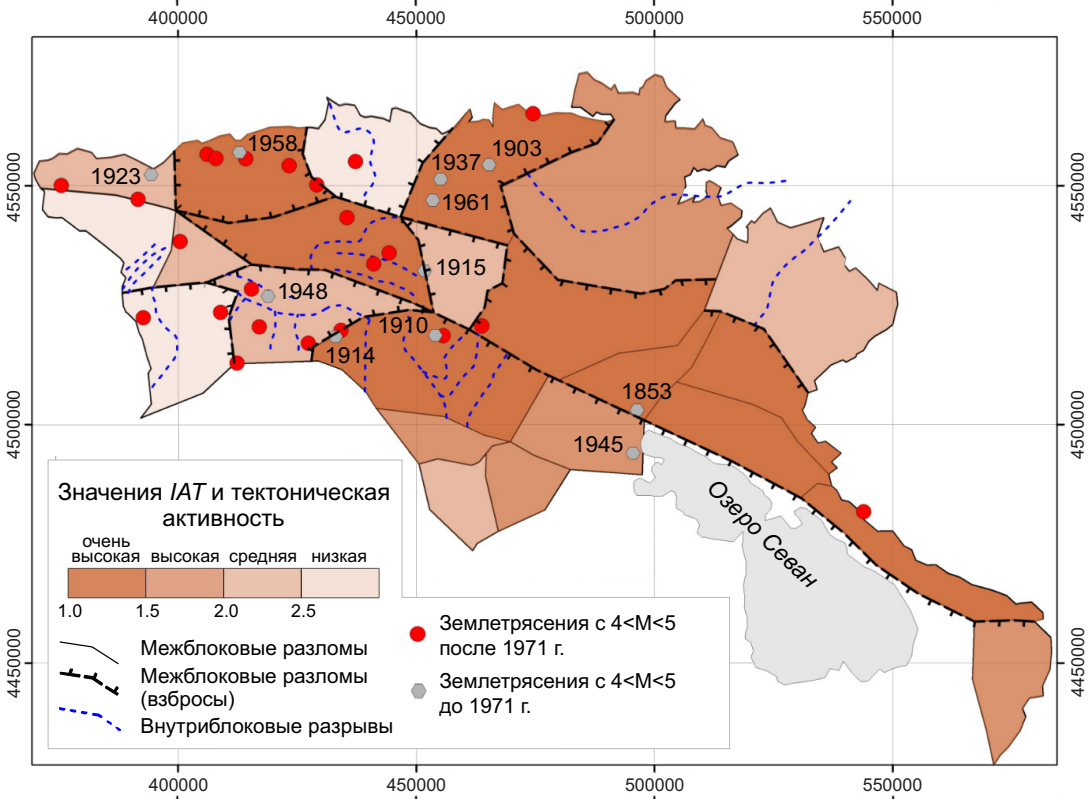

(в)

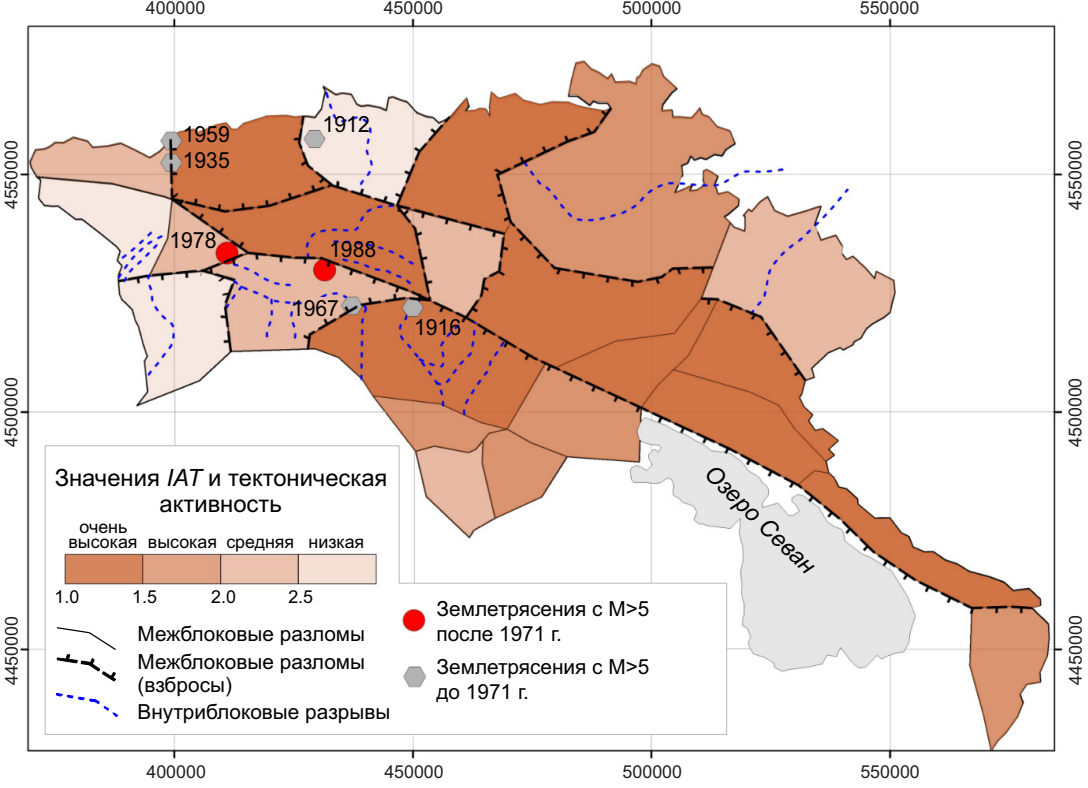

Рис. 2. Пространственное распределение очагов землетрясений: (a) - $2<\mathrm{M}<4$, (б) - 4<M<5, (в) - М>5.

Fig. 2. Spatial distribution of earthquake hypocenters: $(a)-2<\mathrm{M}<4$, (б) $-4<\mathrm{M}<5$, ( $($ ) $)-\mathrm{M}>5$. 
сейсмотектонического потенциала. Но для территории Армении во всех ранее выполненных исследованиях данному обстоятельству не было уделено должного внимания. Только в упомянутой работе [Gabrielyan, Piruzyan, 1972] авторы отмечают, что сильные сейсмические события в основном наблюдаются в приграничных частях геотектонических зон Армении. Однако известно, что каждой из этих зон присуще свое внутреннее сложное блоковое строение, и, следовательно, интерпретация сейсмической активности на таком уровне во многом является обобщенной, что не дает возможности более детально рассмотреть закономерности сейсмической активности внутри самих геотектонических зон. Данное обстоятельство, в свою очередь, обусловливает актуальность настоящей работы.

С целью выявления пространственных закономерностей сейсмической активности нами рассмотрены по отдельности три категории сейсмических событий: слабые $(2<\mathrm{Mb}<4)$, средние $(4<\mathrm{Mb}<5)$ и сильные $(\mathrm{Mb}>5)$. К имеющимся сейсмологическим данным (за 19712018 гг.) для полноты картины были добавлены также данные о землетрясениях региона начиная с 1903 г. Таким образом, общее количество землетрясений составило приблизительно 300 событий, которые в основном являются коровыми (глубина гипоцентров до 50 км). В связи с этим необходимо еще раз отметить, что для периода 1971-2018 гг. нами были подобраны только те сейсмические события, для которых в работе [Burmin et al., 2018] была проведена оценка точности исходных данных и переопределение координат гипоцентров, погрешность лоцирования которых не превышала 5 км. Пространственное распределение землетрясений разных категорий представлено на рис. 2, а сеть сейсмических станций, по которым регистрировались сейсмические события, показана на рис. 3. На рис. 2, а, отчетливо видно, что очаги слабых землетрясений не имеют конкретной пространственной приуроченности к определенным тектоническим единицам и ситуациям. Они наблюдаются как в межблоковых разломно-разрывных зонах, так и во внутриблоковых пространствах - в зонах внутриблоковых разрывов и вне их. В пространственном распределении средних и сильных землетрясений наблюдаются некоторые закономерности. Очаги этих землетрясений в основном распространены в западной части Северной Армении и уже притягиваются к межблоковым разломным зонам. Кроме этого, по большей части известного, факта, наблюдается другая, более важная, закономерность.

Все сильные землетрясения с магнитудой $\mathrm{Mb}>5$ приурочены к тем межблоковым разломно-разрывным зонам, которые отделяют блоки с очень высокой тектонической активностью от блоков средней и низкой активности. Это означает, что для возникновения сильных землетрясений необходимо сочленение блоков с резко отличающимися тектоническими характеристиками. При такой структурно-тектонической обстановке возникают благоприятные условия для накопления напряжения в земной коре и его периодического высвобождения в виде нечастых сильных землетрясений. Что касается сейсмических событий средней величины, с $4<\mathrm{Mb}<5$, то здесь наблюдается почти аналогичная картина.

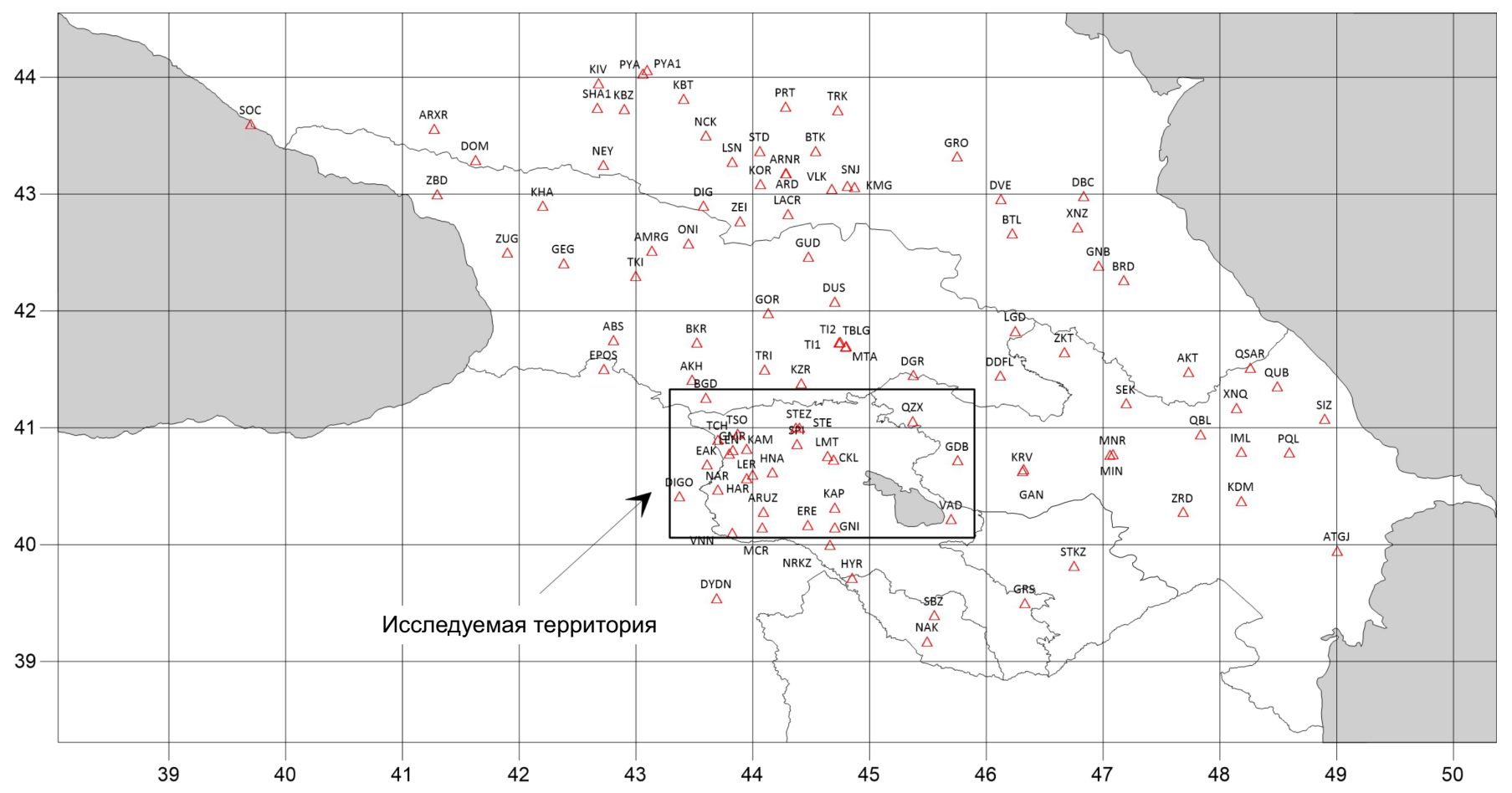

Рис. 3. Сеть сейсмических станций по региону.

Fig. 3. Regional network of seismic stations. 
Разница заключается лишь в том, что в данном случае очаги приурочены также к разломным зонам, разделяющим блоки средней и низкой активности. Это означает, что для возникновения землетрясений средней величины также необходимо сочленение двух блоков с разной тектонической активностью. Однако в данном случае блоки имеют среднюю активность, следовательно, их сейсмотектонический потенциал также более низкий по сравнению с блоками с очень высокой тектонической активностью.

Примечательно также то, что данные сегменты разломов, согласно [Bal'yan, 1969; Milanovsky, 1968; Gabrielyan et al., 1981], являются в основном взбросо-сдвигами, оконтуривающими морфоструктурные единицы горстового характера (Базумский, Джавахетский, Памбакский, Халабский и др.). При такой структурно-тектонической обстановке в разломной зоне при возникновении средних и сильных землетрясений возможно резкое смещение одного блока по отношению к другому, по нашему предположению преимущественно взбросо-сдвигового характера. Для подтверждения данного предположения были изучены также механизмы землетрясений с $\mathrm{Mb}>4$ (рис. 4, табл. 2).

Примечателен тот факт, что для механизмов очагов землетрясений, которые приурочены к межблоковым разломно-разрывным зонам (к неотектоническим

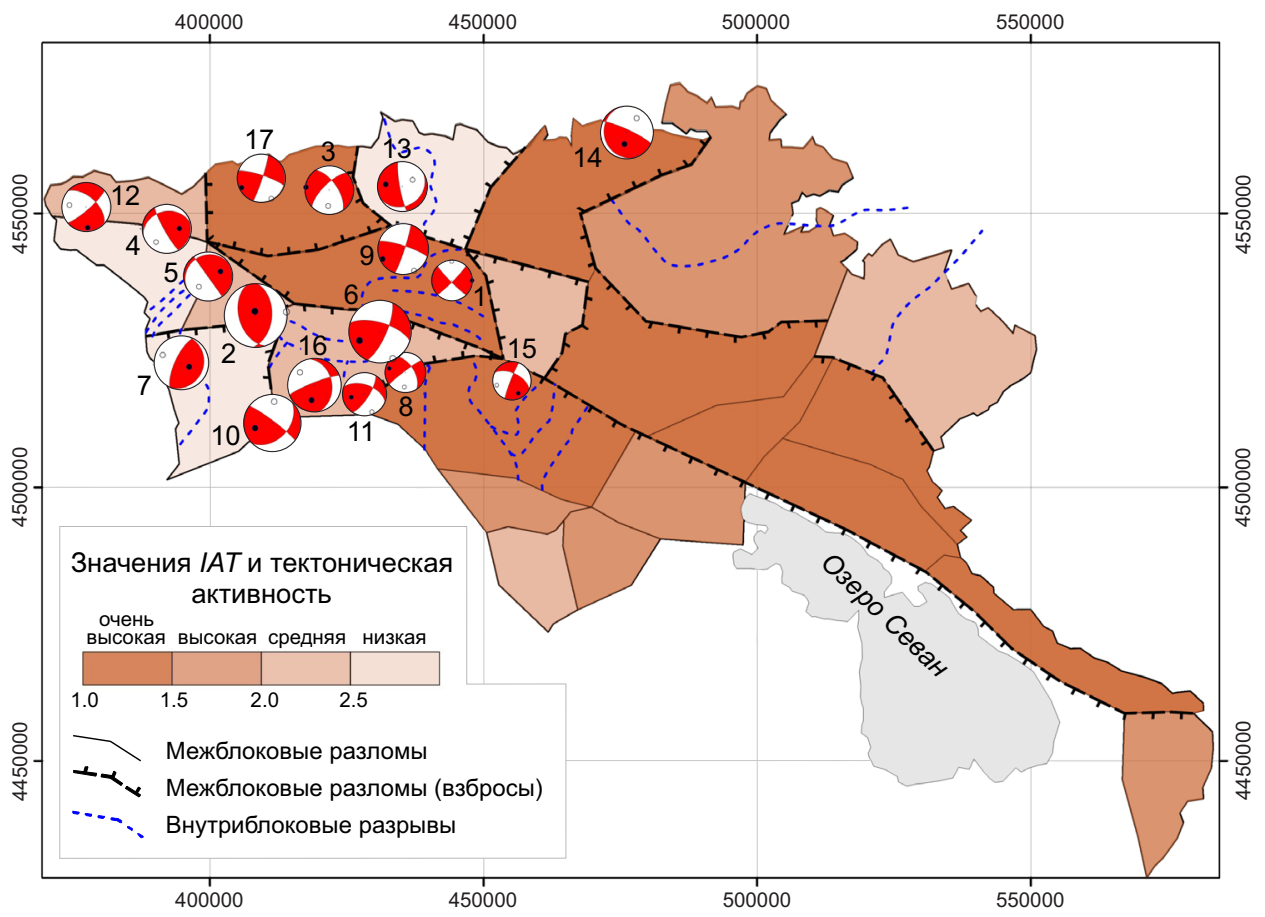

Рис. 4. Механизмы очагов землетрясений с М>4 за 1978-2012 гг.

Fig. 4. Earthquake focal mechanisms for the period from 1978 to 2012 (M>4).

Таблица 2. Параметры фокальных механизмов для землетрясений с M>4

Table 2. Parameters of earthquake focal mechanisms $(M>4)$

\begin{tabular}{|c|c|c|c|c|c|c|c|c|c|c|c|c|}
\hline \multirow{2}{*}{ № } & \multirow{2}{*}{ Дата } & \multicolumn{2}{|c|}{ Ось сжатия Р } & \multicolumn{2}{|c|}{ Ось растяжения Т } & \multicolumn{2}{|c|}{$\begin{array}{c}\text { Промежуточная } \\
\text { ось }\end{array}$} & \multirow{2}{*}{$\begin{array}{l}\text { Нодальные } \\
\text { плоскости }\end{array}$} & \multirow{2}{*}{ STR } & \multirow{2}{*}{ DIP } & \multirow{2}{*}{ SLIP } & \multirow{2}{*}{$\begin{array}{c}\text { Решение } \\
\text { механизмов }\end{array}$} \\
\hline & & $\mathrm{Az}$ & $\alpha$ & $\mathrm{Az}$ & $\alpha$ & $\mathrm{Az}$ & $\alpha$ & & & & & \\
\hline \multirow[b]{2}{*}{1} & \multirow[b]{2}{*}{ 17.01.1978 } & \multirow[b]{2}{*}{360.0} & \multirow[b]{2}{*}{8.1} & \multirow[b]{2}{*}{90.0} & \multirow[b]{2}{*}{0.0} & \multirow[b]{2}{*}{180.0} & \multirow[b]{2}{*}{81.9} & 1 & 44.7 & 82.7 & -5.8 & \\
\hline & & & & & & & & 2 & 135.3 & 84.3 & -174.3 & \\
\hline \multirow{2}{*}{2} & \multirow{2}{*}{ 22.01.1978 } & \multirow{2}{*}{83.7} & \multirow{2}{*}{0.0} & \multirow{2}{*}{353.7} & \multirow{2}{*}{79.6} & \multirow{2}{*}{173.7} & \multirow{2}{*}{10.4} & 1 & 3.9 & 45.9 & 104.5 & \\
\hline & & & & & & & & 2 & 163.5 & 45.9 & 75.5 & \\
\hline \multirow[b]{2}{*}{3} & \multirow{2}{*}{ 27.06.1978 } & \multirow{2}{*}{183.3} & \multirow{2}{*}{33.4} & \multirow{2}{*}{276.6} & \multirow{2}{*}{5.0} & \multirow{2}{*}{14.0} & \multirow{2}{*}{56.1} & 1 & 225.1 & 70.9 & -28.5 & \\
\hline & & & & & & & & 2 & 325.2 & 63.2 & -158.5 & \\
\hline
\end{tabular}


Таблица 2 (продолжение)

Table 2 (continued)

\begin{tabular}{|c|c|c|c|c|c|c|c|c|c|c|c|c|}
\hline \multirow{2}{*}{ № } & \multirow{2}{*}{ Дата } & \multicolumn{2}{|c|}{ Ось сжатия Р } & \multicolumn{2}{|c|}{ Ось растяжения T } & \multicolumn{2}{|c|}{$\begin{array}{c}\text { Промежуточная } \\
\text { ось }\end{array}$} & \multirow{2}{*}{$\begin{array}{l}\text { Нодальные } \\
\text { плоскости }\end{array}$} & \multirow{2}{*}{ STR } & \multirow{2}{*}{ DIP } & \multirow{2}{*}{ SLIP } & \multirow{2}{*}{$\begin{array}{c}\text { Решение } \\
\text { механизмов }\end{array}$} \\
\hline & & $\mathrm{Az}$ & $\alpha$ & $\mathrm{Az}$ & $\alpha$ & $\mathrm{Az}$ & $\alpha$ & & & & & \\
\hline \multirow[b]{2}{*}{4} & \multirow[b]{2}{*}{ 24.04.1979 } & \multirow[b]{2}{*}{217.1} & \multirow[b]{2}{*}{31.0} & \multirow[b]{2}{*}{89.8} & \multirow[b]{2}{*}{45.2} & \multirow[b]{2}{*}{326.3} & \multirow[b]{2}{*}{28.7} & 1 & 150.7 & 82.1 & 119.0 & \\
\hline & & & & & & & & 2 & 254.6 & 30.0 & 16.0 & \\
\hline \multirow[b]{2}{*}{5} & \multirow[b]{2}{*}{17.12 .1983} & \multirow[b]{2}{*}{219.9} & \multirow[b]{2}{*}{43.1} & \multirow[b]{2}{*}{69.0} & \multirow[b]{2}{*}{43.1} & \multirow[b]{2}{*}{324.5} & \multirow[b]{2}{*}{15.1} & 1 & 324.5 & 90.0 & -105.1 & \\
\hline & & & & & & & & 2 & 234.5 & 15.1 & -368.3 & \\
\hline \multirow{2}{*}{6} & \multirow{2}{*}{07.12 .1988} & & & & & & & 1 & 24.0 & 73.2 & 24.6 & \\
\hline & & 154.2 & 4.4 & 246.6 & 29.1 & 56.3 & 60.5 & 2 & 286.4 & 66.5 & 161.5 & \\
\hline & & & & & & & & 1 & 204.5 & 72.0 & 91.8 & \\
\hline 7 & 08.12.1988 & 293.1 & 27.0 & 117.3 & 63.0 & 24.0 & 1.7 & 2 & 18.7 & 18.1 & 84.5 & \\
\hline & & & & & & & & 1 & 232.4 & 84.9 & -34.6 & \\
\hline 8 & 12.12 .1988 & 183.5 & 27.6 & 284.2 & 20.0 & 45.0 & 55.1 & 2 & 326.0 & 55.6 & -173.4 & \\
\hline & & & & & & & & 1 & 354.3 & 66.1 & 153.7 & \\
\hline (3) & 24.01 .1989 & 253.0 & 0.0 & 315.0 & 34.9 & 135.0 & 33.1 & 2 & 95.7 & 66.1 & 26.3 & \\
\hline & & & & & & & & 1 & 306.9 & 83.3 & 131.7 & \\
\hline 10 & 90.03.1909 & 3.4 & 26.2 & 233.2 & $3 / .4$ & 121.0 & 41.3 & 2 & 44.5 & 42.1 & 10.1 & \\
\hline & & & & & & & & 1 & 32.2 & 72.5 & 38.2 & \\
\hline & 21.05 .1990 & 150.0 & 11.8 & 256.6 & 39.0 & 53.1 & 40.0 & 2 & 288.9 & 53.9 & 158.2 & \\
\hline & & & & & & & & 1 & 48.9 & 79.3 & -144.5 & \\
\hline 12 & 18.02 .1992 & 276.0 & 32.3 & 175.6 & 15.8 & 63.4 & 53.1 & 2 & 311.3 & 55.2 & -13.1 & \\
\hline & & & & & & & & 1 & 169.7 & 81.6 & -110.7 & \\
\hline 13 & 04.02 .2002 & & & 277.1 & & 172.9 & 20.5 & 2 & 58.5 & 22.3 & -22.7 & \\
\hline & & & & & & & & 1 & 294.8 & 81.1 & 78.3 & \\
\hline 14 & 13.11 .2005 & 34.8 & 35.2 & 191.2 & 52.4 & 296.6 & 11.5 & 2 & 168.2 & 14.6 & 142.5 & \\
\hline & & & & & & & & 1 & 201.5 & 85.0 & 146.4 & \\
\hline 15 & 16.12 .2005 & 252.9 & 19.1 & 152.8 & 26.8 & 14.0 & 56.1 & 2 & 294.8 & 56.6 & 6.0 & \\
\hline & & & & & & & & 1 & 248.4 & 82.5 & 123.7 & \\
\hline & 20.05 .2012 & 311.7 & 29.4 & 190.6 & 42.5 & 63.4 & 33.4 & 2 & 349.5 & 34.4 & 13.4 & \\
\hline & & & & & & & & 1 & 184.7 & 84.8 & 10.3 & \\
\hline 17 & 29.06 .2012 & 152.7 & 3.5 & 243.3 & 10.9 & 45.0 & 78.5 & 2 & 287.5 & 79.8 & 174.7 & \\
\hline
\end{tabular}


взбросам), преобладающим типом подвижек также являются взбросы со сдвиговым компонентом. Исключение составляют некоторые очаги, которые имеют внутриблоковое расположение. Для них механизмы очагов имеют в основном сбросо-сдвиговый характер.

В других частях исследуемой территории, где граничащие между собой блоки имеют схожую тектоническую активность, в большей мере наблюдаются сейсмические события низкой величины.

\section{4. ЗАКЛЮЧЕНИЕ}

В результате проведенного исследования можно сделать вывод, что структурно-тектоническая ситуация, установленная на неотектоническом этапе, обусловливает общий характер сейсмической активности территории, в связи с чем наблюдается пространственное распределение очагов сейсмических событий разной величины. Очаги сильных землетрясений с $\mathrm{Mb}>5$ на территории Северной Армении, как показали исследования, в основном приурочены к разломным зонам, отделяющим блоки с резко отличающейся тектонической активностью. Стоит еще раз отметить, что речь идет не о современной тектонической активности блоков, а об их неотектонической активности, которая характеризует общее направление и тенденции тектонического развития территории за длительный промежуток времени. Изучение современных тектонических движений важно с позиции выявления возможных зон накопления напряжений в земной коре и прогноза землетрясений в кратковременной перспективе. Однако для выделения очаговых зон сильных землетрясений или для оценки сейсмотектонического потенциала разломов основное внимание нужно переключать на неотектонические движения и связанную с ними структурно-тектоническую ситуацию на изучаемой территории. Примененный в статье подход дает возможность проведения дальнейших исследований в направлении более объективной оценки сейсмотектонического потенциала разломов, которая не основывается лишь на анализе произошедших ранее сейсмических событий.

\section{5. ЛИТЕРАТУРA / REFERENCES}

Arefiev S.S., 2003. Epicenter Seismological Studies. Akademkniga, Moscow, 374 p. (in Russian) [Арефьев С.С. Эпицентральные сейсмологические исследования. М.: Академкнига, 2003. 374 с.].

Bal'yan S.P., 1969. Structural Geomorphology of the Armenian Highlands and Bordering Areas. YSU Publishing House, Yerevan, 390 p. (in Russian) [Бальян С.П. Структурная геоморфология Армянского нагорья и окаймляющих областей. Ереван: Изд-во ЕГУ, 1969. 390 с.].

Bal'yan S.P., Lilienberg D.A., Milanovsky E.E., 1989. The Latest and Modern Tectonics of Seismically Active Orogens in Armenia and the Spitak Earthquake Region. Geomorphology 4, 11-13 (in Russian) [Бальян С.П., Лилиенберг Д.А., Милановский Е.Е. Новейшая и современная тектоника сейсмоактивных орогенов Армении и района
Спитакского землетрясения // Геоморфология. 1989. № 4. C. 11-13].

Burmin V.Yu., Shemeleva I.B., Fleifel L.D., Avetisyan A.M., Ghazaryan K.S., 2016. Results of Seismological Data Processing for the Territory of Armenia. Issues of Engineering Seismology 43 (1), 29-39 (in Russian) [Бурмин В.Ю., Шемелева И.Б., Флейфель Л.Д., Аветисян А.М., Казарян К.С. Результаты обработки сейсмологических данных для территории Армении // Вопросы инженерной сейсмологии. 2016. Т. 43. № 1. С. 29-39].

Burmin V.Yu., Shemeleva I.B., Fleifel L.D., Avetisyan A.M., Ghazaryan K.S., 2018. Spatial Distribution of Crustal Earthquakes in the Caucasus. Issues of Engineering Seismology 45 (1), 39-48 (in Russian) [Бурмин В.Ю., Шемелева И.Б., Флейфель Л.Д. Аветисян А.М., Казарян К.С. Пространственное распределение коровых землетрясений Кавказа // Вопросы инженерной сейсмологии. 2018. Т. 45. № 1. C. 39-48]. https://doi.org/10.21455/VIS2018.1-4.

Etchebehere M.L.C., Saad A.R., Santoni G.C., Casado F.C., Fulfaro V.J., 2006. Detection of Probable Neotectonic Deformations in the Rio Do Peixe Valley, Western Region of São Paulo, Using RDE (Declivity-Extension Ratio) Indices in Drainage Segments. Geosciences 25 (3), 271-287.

Gabrielyan A.A., Piruzyan S.A., 1972. Seismotectonic Schematic Map of Armenia and Adjacent Parts of the AnteCaucasus. Bulletin of the Armenian SSR Academy of Sciences, Earth Sciences 4, 24-33 (in Russian) [Габриелян А.А., Пирузян С.A. Сейсмотектоническая схема Армении и сопредельных частей Антикавказа // Известия АН АрмССР. Науки о Земле. 1972. № 4. С. 24-33].

Gabrielyan A.A., Sargsyan O.A., Simonyan G.P., 1981. Seismotectonics of the Armenian SSR. YSU Publishing House, Yerevan, 284 p. (in Russian) [Габриелян А.А., Саркисян O.A., Симонян Г.П. Сейсмотектоника Армянской ССР. Ереван: Изд-во ЕГУ, 1981. 284 с.].

Gentana D., Sulaksana N., Sukiyah E., Yuningsih E., 2018. Index of Active Tectonic Assessment: Quantitative-Based Geomorphometric and Morphotectonic Analysis at Way Belu Drainage Basin, Lampung Province, Indonesia. International Journal of Advanced Science Engineering Information Technology 8 (6), 2460-2471.

Karapetyan N.K., 1988. The Crustal Block Structure of Armenian Highlands. Bulletin of the Armenian SSR Academy of Sciences, Earth Sciences XLI (6), 19-28 (in Russian) [Карапетян Н.К. Блоковое строение земной коры Армянского нагорья // Известия АН АрмССР. Науки о Земле. 1988. T. XLI. № 6. С. 19-28].

Lander A.V., 2004. The FA2002 Program System to Determine the Focal Mechanisms of Earthquakes in Kamchatka, the Commander Islands and the Northern Kuriles. Petropavlovsk-Kamchatsky: Report KEMSD GS RAS. 250 p.

Mahmood S., Gloaguen R., 2012. Appraisal of Active Tectonics in Hindu Kush: Insights from DEM Derived Geomorphic Indices and Drainage Analysis. Geoscience Frontiers 3 (4), 407-428. https://doi.org/10.1016/j.gsf.2011.12.002.

Milanovsky E.E., 1968. Modern Tectonics of the Caucasus. Nedra, Moscow, 483 p. (in Russian) [Милановский Е.Е. Новейшая тектоника Кавказа. М.: Недра, 1968. 483 с.]. 
Moussi A., Rebai N., Chaieb A., Saadi A., 2018. GIS-Based Analysis of the Stream Length-Gradient Index for Evaluating Effects of Active Tectonics: A Case Study of Enfidha (North-East of Tunisia). Arabian Journal of Geosciences 11 (123). https://doi.org/10.1007/s12517-018-3466-x.

Simonyan G.P., 1995. On the New Map of Neotectonics of the Armenia Territory. YSU Scientific Papers 1, 94-99 (in Russian] [Симонян Г.П. О новой карте неотектоники территории Армении //Ученые записки ЕГУ. 1995. № 1. C. 94-99].

Singh O., Sarangi A., Milap C., 2008. Hypsometric Integral Estimation Methods and its Relevance on Erosion Status of North-Western Lesser Himalayan Watersheds. Water Resour Manage 22, 1545-1560. https://doi.org/10.1007/s1 1269-008-9242-z.

Volchanskaya I.K., Dzhrbashyan R.T., Meliksetyan B.M., Sargsyan O.A., Favorskaya M.A., 1971. The Block Structure of North-Western Armenia and the Features of Distribution of Igneous and Ore Occcurences. Soviet Geology 8, 15-27 (in Russian) [Волчанская И.К., Джрбашян Р.Т., Меликсетян Б.М., Саркисян О.А., Фаворская М.А. Блоковое строение Северо-Западной Армении и особенности размещения магматических и рудных проявлений // Советская геология. 1971. № 8. С. 15-27]. 